\title{
对亚苯基桥联双脲基嘧啶酮衍生物的超分子自组装研究
}

\begin{tabular}{|c|c|c|c|c|c|}
\hline 齐丽杰 $a$ & & 逸涵 $b$ & 肖唐金金 $*, a$ & 吴浩然 ${ }^{a}$ & ᄀ 凯 ${ }^{a}$ \\
\hline 鲍 成 ${ }^{a}$ & 申 & 永 ${ }^{a}$ & 李正义 ${ }^{a}$ & 孙小强 $^{a}$ & 王乐勇 $*, a, b$ \\
\hline
\end{tabular}

\begin{abstract}
摘要 超分子聚合物被认为是一种新型的动态材料，对超分子聚合过程的研究不仅有助于理解自组装规律，而且为开 发智能材料提供理论支持. 研究了对亚苯基桥联的双胀基嘧啶酮(UPy)衍生物 M1 M3 的四重氢键超分子聚合. 这些 单体分子之间的唯一区别是其间隔基(臭聚乙二醇)的长度不同. 通过测试随单体浓度变化的 ${ }^{1} \mathrm{H}$ NMR, NOESY 和粘度 等研究了这些单体分子基于环链平衡的超分子聚合行为. 结果表明间隔基长度对开环超分子聚合过程有显著影响. 其 原因是环状单体中亚苯基与二聚 UPy 之间的 $\pi-\pi$ 相互作用强度不同. 具有最短间隔基的 M1 缺乏 $\pi-\pi$ 作用，而具有最长 间隔基的 M3 具有较弱的 $\pi-\pi$ 作用，因此二者的临界聚合浓度都较低; 相比之下，间隔基长度适中的 $\mathbf{M} 2$ 具有较强的 $\pi-\pi$ 作用, 从而导致其有较高的临界聚合浓度 $\left(189 \mathrm{mmol} \cdot \mathrm{L}^{-1}\right)$. 最后, 进一步研究了 M1 M3 与缺电子环番 “blue-box”之 间的相互作用，显示只有 $\mathbf{M 3}$ 与环番发生主客体作用. 该模型促进了对分子结构与超分子聚合之间紧密关系的认识，这 对精确调控超分子聚合以及开发定制材料都具有重要意义.
\end{abstract}

关键词＼cjkstart超分子化学；四重氢键；自组装；超分子聚合物；大环；主客体作用

\section{Supramolecular Self-Assembly of Dioxyphenylene Bridged Ureidopyrimidinone Derivatives}

\author{
Qi, Lijie ${ }^{a}$ \\ Ding, Yihan ${ }^{b}$ \\ Xiao, Tangxin ${ }^{*, a}$ \\ $\mathrm{Wu}$, Haoran $^{a}$ \\ Diao, $\mathrm{Kai}^{a}$ \\ Bao, Cheng ${ }^{a}$ \\ Shen, Yong ${ }^{a} \quad$ Li, Zhengyi $^{a} \quad$ Sun, Xiaoqiang ${ }^{a} \quad$ Wang, Leyong ${ }^{*, a, b}$ \\ ( ${ }^{a}$ School of Petrochemical Engineering, Changzhou University, Changzhou, Jiangsu 213164) \\ ( ${ }^{b}$ School of Chemistry and Chemical Engineering, Nanjing University, Nanjing 210023)
}

\begin{abstract}
Supramolecular polymers are regarded as a new kind of dynamic materials. The study of supramolecular polymers not only helps to understand the law of self-assembly, but also provides theoretical support for the development of smart materials. Herein, three dioxyphenylene bridged ditopic ureidopyrimidinone (UPy) derivatives M1 $\sim$ M3 are studied. These molecules could undergo supramolecular polymerization via quadruple hydrogen bonding. The only difference in their structure is the length of the oligo(ethylene oxide) chain as spacers. The supramolecular polymerization based on ring-chain equilibrium of these molecules were studied by a series of experiments including concentration-dependent ${ }^{1} \mathrm{H}$ NMR, NOESY, and viscosity measurement, which showed that the spacer length has a big impact on the ring-opening supramolecular polymerization process. And the main reason for this is the different strengths of $\pi-\pi$ interaction between the dioxyphenylene unit and the dimerized UPy motif in the cyclic monomer form. M1 with the shortest spacer lacks this kind of $\pi-\pi$ interaction while M3 with the longest spacer possesses a weak $\pi-\pi$ interaction, both leading to small value of CPCs. By contrast, M2 with a moderate length of spacer has a strong $\pi-\pi$ interaction, resulting in a high CPC value $\left(189 \mathrm{mmol} \cdot \mathrm{L}^{-1}\right)$. Finally, the host-guest complexation between $\mathbf{M 1} \sim \mathbf{M 3}$ with the $\pi$-electron deficient bipyridinium-based cyclophane "blue-box" were further investigated, which shows that only M3 could perform host-guest complexation. From this interesting model, new insight into the relationship between molecular structure and supramolecular polymerization is discovered, which is important for creating tailor-made supramolecular polymeric materials.
\end{abstract}

\footnotetext{
* Corresponding authors. E-mail: xiaotangxin@cczu.edu.cn; lywang@nju.edu.cn Received June 29, 2020; revised July 27, 2020; published online August 5, 2020 Dedicated to the 40th anniversary of Chinese Journal of Organic Chemistry.

Project supported by the National Natural Science Foundation of China (No. 21702020).

国家自然科学基金(No. 21702020)资助项目.
} 
Keywords supramolecular chemistry; quadruple hydrogen bonds; self-assembly; supramolecular polymer; macrocycles; host-guest interaction

\section{Introduction}

Supramolecular polymers (SPs) are dynamic materials constructed from monomeric units via reversible non-covalent interactions. ${ }^{[1-5]}$ In recent years, many interesting SPs have been constructed by different non-covalent interactions, including multiple hydrogen bonds, ${ }^{[6-8]} \pi-\pi$ interaction, ${ }^{[9]}$ metal-ligand coordination, ${ }^{[10-12]}$ halogen bond, ${ }^{[13]}$ host-guest interaction, ${ }^{[14-21]}$ or a combination of them. For example, Liu and co-workers ${ }^{[22]}$ reported a supramolecular ternary polymer fabricated by cucurbituril and cyclodextrin. $\mathrm{Li}$, Zhao and co-workers ${ }^{[23]}$ reported a very interesting hydrogen bonding-driven supramolecular alternate block copolymers which could be tuned by ion-pair binding. Huang and co-workers ${ }^{[24]}$ reported a series of SPs formed by orthogonal self-assembly based on metal-ligand and host-guest interactions. Ureidopyrimidinone (UPy), which is a self-complementary quadruple hydrogen bonding unit reported by Meijer and co-workers, ${ }^{[25]}$ is a widely used supramolecular polymerization building block on account of its high binding constant $\left(K_{\text {dimer }}>10^{7} \mathrm{~L} \cdot \mathrm{mol}^{-1}\right.$ in $\left.\mathrm{CHCl}_{3}\right)$. Since then, an increasing number of functional SPs have been constructed from UPy. ${ }^{[26-33]}$ In recent years, our group ${ }^{[34-36]}$ has also been working on constructing various UPy-based supramolecular complexes.

As mentioned above, $\pi-\pi$ interaction is also an important non-covalent interaction besides hydrogen bonding in supramolecular chemistry. Interestingly, the UPy unit can not only form dimer via quadruple hydrogen bonding but also can undergo $\pi-\pi$ stacking behavior. ${ }^{[37]}$ More recently, we ${ }^{[38]}$ reported a UPy-based supramolecular polymerization system, in which supramolecular polymerization of different monomers could be regulated by introducing $\pi-\pi$ interaction to the monomer. In that work, the strength of the $\pi-\pi$ interaction depends on the orientation and the size of the aromatic groups, which localized at the central of the spacer of the ditopic UPy monomer. Herein, we aim to take a step forward to investigate the impact of spacer length on the supramolecular polymerization of dioxyphenylene bridged ditopic UPys. To this end, three ditopic UPy derivatives M1 $\sim$ M3 were prepared, the only difference of which is the spacer length between two UPy units (Figure 1). By studying this interesting model, we would like to have an insight into the relationship between molecular structure and supramolecular polymerization, which is important to produce tailor-made SPs with functional properties.

\section{Results and discussion}

The synthesis of M1 $\sim \mathbf{M 3}$ is straightforward (Scheme 1). The preparation of $\mathbf{M} 2$ and $\mathbf{M 3}$ is according to our previous report. ${ }^{[38-39]}$ Coupling of the ditopic amine compound 1a with 1,1'-carbonyldiimidazole (CDI) activated alkylsubstituted pyrimidinone 2 resulted in the targeted UPy

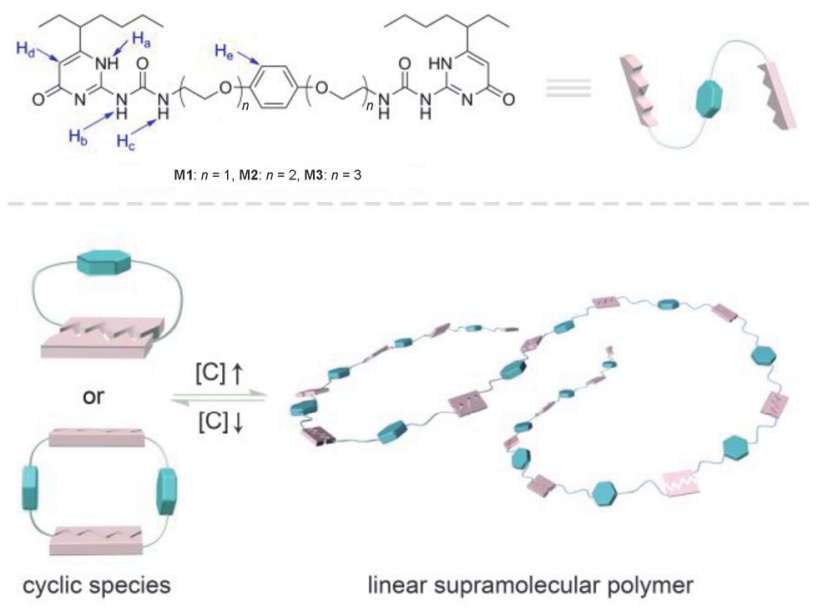

Figure 1 Chemical structures of $\mathbf{M 1} \sim \mathbf{M} 3$ and cartoon representation of their ring-opening supramolecular polymerization process<smiles>CCCCC(CC)c1cc(=O)nc(NC(=O)n2ccnc2)[nH]1</smiles><smiles>CCCCC(CC)c1cc(=O)nc(NC(=O)NCCOc2ccc(OCC(C)(C)NC(=O)Nc3nc(=O)cc(C(CC)CCCC)[nH]3)cc2)[nH]1</smiles>

Scheme 1 Synthesis of M1 $\sim$ M3

monomer M1, which was fully characterized by ${ }^{1} \mathrm{H}$ NMR, ${ }^{13} \mathrm{C}$ NMR and HR-MS.

Ring-chain equilibrium is an important supramolecular polymerization mechanism, which shows that linear SP species are in equilibrium with their cyclic monomers or oligomers in one system. ${ }^{[40]}$ During the polymerization process, there exists a critical polymerization concentration (CPC), below which the cyclic species, for example, cyclic monomers or cyclic dimers, are predominant. But above $\mathrm{CPC}$, the linear SPs are the main products in the system. Previously, we ${ }^{[39,41-42]}$ have studied the ring-chain mechanism by incorporating functional group into the ditopic UPy monomers. In this study, the supramolecular polymerization of $\mathbf{M 1} \sim \mathbf{M 3}$ also follows ring-chain mechanism. Herein, M1 forms cyclic dimer while both M2 and M3 form cyclic monomers below CPC and SPs above CPC.

The supramolecular polymerization behaviors of M1 M3 were firstly studied by concentration-dependent ${ }^{1} \mathrm{H}$ 
NMR. As shown from Figure 2, the characteristic amide proton signals located in the down field region $\left(\mathrm{H}_{1}, \mathrm{H}_{2}\right.$ and $\mathrm{H}_{3}$; between $\delta 9$ and 14), indicating all the UPy units from M1 M3 exist in dimerization form via quadruple hydrogen bonding. Figure $2 \mathrm{a}$ shows the concentration-varied ${ }^{1} \mathrm{H}$ NMR spectra of M1. At low concentration $\left(8 \mathrm{mmol} \cdot \mathrm{L}^{-1}\right)$, two sets of peaks appeared, represent the cyclic dimer and the linear polymer respectively. Due to the short spacer of

(a)

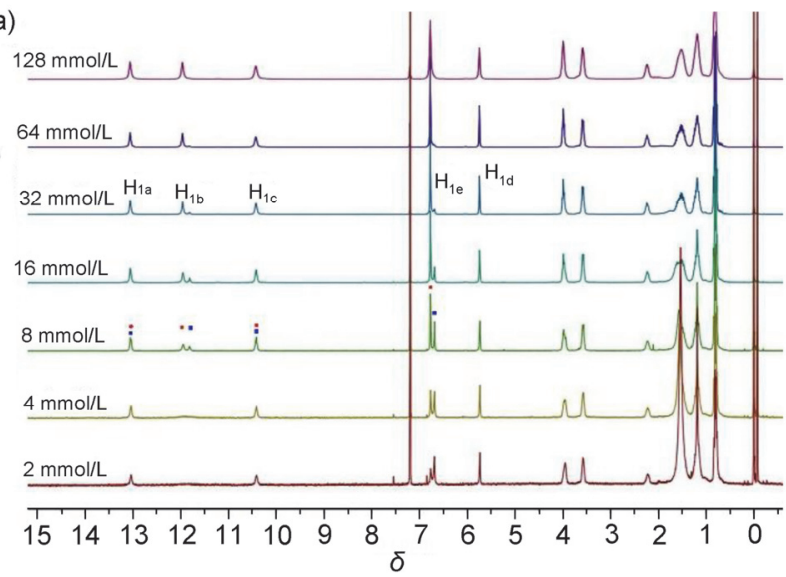

(b)

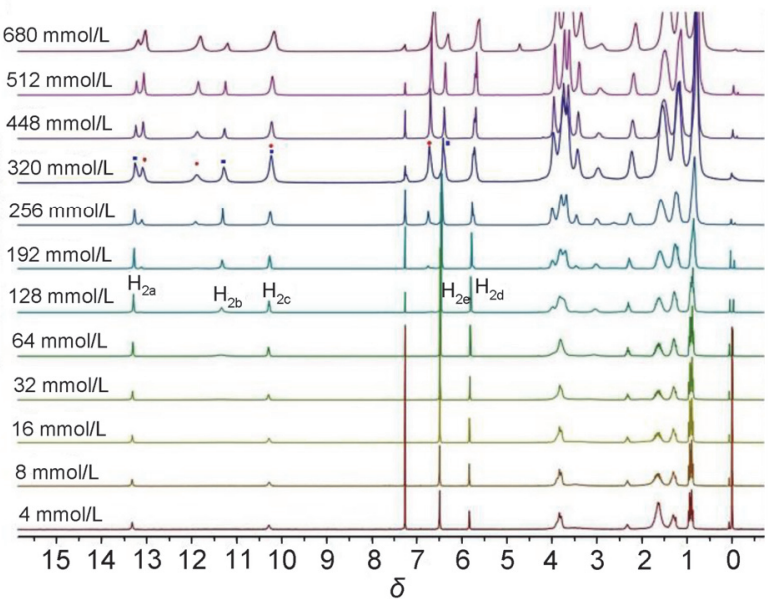

(c)

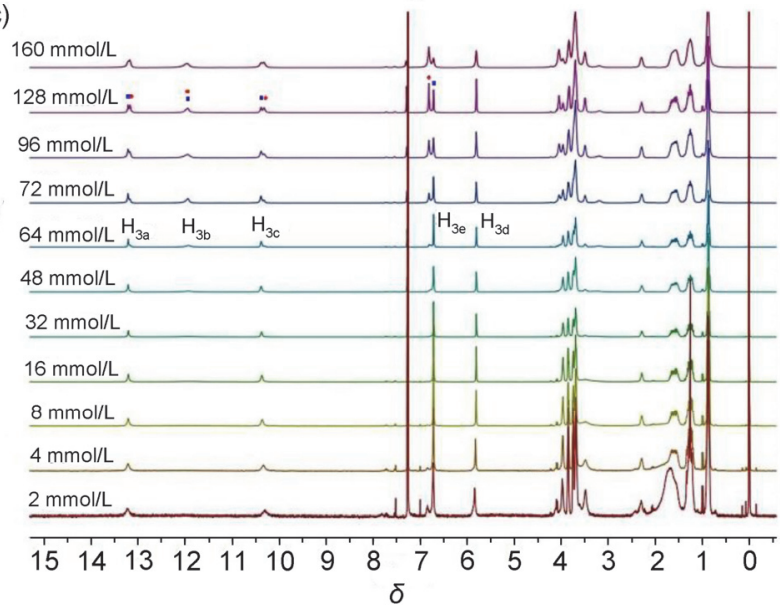

Figure $2{ }^{1} \mathrm{H}$ NMR spectra $\left(300 \mathrm{MHz}, \mathrm{CDCl}_{3}, 298 \mathrm{~K}\right)$ of $\mathbf{M 1}$ (a), M2 (b), and M3 (c) at different monomer concentrations The blue squares indicate cyclic species and the red dots stand for polymeric assemblies
M1 $(n=1)$, cyclic dimers should be the smallest species below CPC. As the concentration increased, the peaks representing cyclic dimers gradually disappeared and only one set of peaks remained, which was corresponding to linear SPs. Moreover, the CPC of M1 was calculated based on $\mathrm{H}_{1 \mathrm{e}}$ by plotting the concentration of cyclic monomer versus the total monomer concentration. Therefore, a CPC of 5 $\mathrm{mmol} \cdot \mathrm{L}^{-1}$ for $\mathbf{M 1}$ was calculated (Figure 3 ).

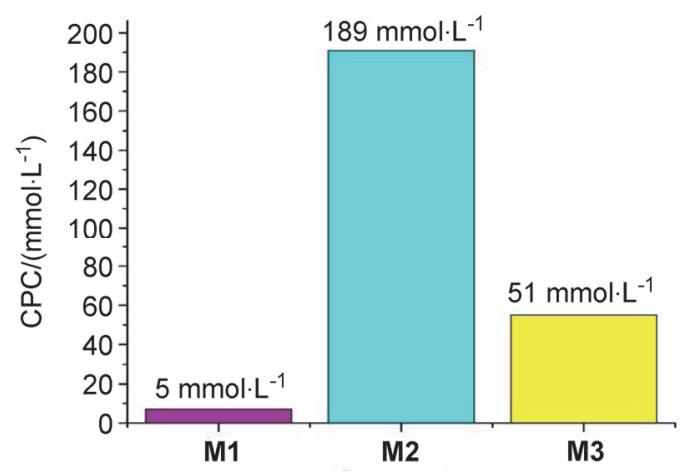

Figure 3 CPC values of M1, M2, and M3 calculated from ${ }^{1} \mathrm{H}$ NMR

The ${ }^{1} \mathrm{H}$ NMR spectra of M2 showed a concise picture with only one set of peaks until the concentration increased to $192 \mathrm{mmol} \cdot \mathrm{L}^{-1}$ (Figure $2 \mathrm{~b}$ ), indicating that it's not easy for $\mathbf{M} 2$ to undergo a ring-opening polymerization process. With the increase of the concentration, a new set of peaks representing the linear SPs appeared and their intensity increased gradually. This is because the spacer in $\mathbf{M} 2$ is long enough to form a cyclic monomer, which generates a $\pi-\pi$ interaction between the dimerized UPy plane and the dioxyphenylene group. The additional $\pi-\pi$ interaction greatly stabilizes the quadruple hydrogen bonded cyclic monomer structure, which makes ring-opening of $\mathbf{M} 2$ much more difficult. During the ring-opening supramolecular polymerization process, $\mathrm{H}_{2 \mathrm{c}}$ and $\mathrm{H}_{2 \mathrm{e}}$ displayed obvious downfield shifts (from $\delta 11.27$ to 11.87 for $\mathrm{H}_{2 \mathrm{c}}$, from $\delta 6.39$ to 6.69 for $\mathrm{H}_{2 \mathrm{e}}$ ), reflecting the loss of shielding effect between the dioxyphenylene group and the dimerized UPy motif. Meanwhile, the signals of $\mathrm{H}_{2 \mathrm{a}}$ and $\mathrm{H}_{2 \mathrm{~d}}$ moved a little to upfield upon ring-opening, suggesting that these protons are located at the edge of the phenylene ring in the cyclic structure. Notably, all proton signals in M2 became broad at high concentration, revealing the formation of large molecular weight SPs. A CPC value of $189 \mathrm{mmol} \cdot \mathrm{L}^{-1}$ for $\mathbf{M 2}$ was calculated based on $\mathrm{H}_{2 \mathrm{e}}$ (Figure 3 ).

What will happen if we further increase the length of the spacer? To clarify this problem, the molecule M3 with $n=3$ was designed and synthesized. ${ }^{1} \mathrm{H}$ NMR experiments showed that $\mathbf{M 3}$ is neither as difficult as M2 nor as easy as M1 for ring-opening polymerization. The ring-opening of M3 happened at around $64 \mathrm{mmol} \cdot \mathrm{L}^{-1}$ (Figure 2c). There is no doubt that $\mathbf{M 3}$ can form cyclic monomers below CPC due to its long spacer. Compared with M2, the distance between the dioxyphenylene group and the dimerized UPy motif in the cyclic form of M3 is longer, leading to a weaker 
$\pi-\pi$ interaction between them and make the cyclic structure of M3 less stable than M2. However, the cyclic monomer structure of M3 is more stable than the cyclic dimer structure of M1 due to the additional $\pi-\pi$ interaction, although it is weak. As a result, the CPC of M3 is much less than M2 but higher than $\mathbf{M} 1$ and was calculated to be $51 \mathrm{mmol} \cdot \mathrm{L}^{-1}$ (Figure 3).

NOESY of M2 further evidenced its cyclic monomer structure below CPC. As shown from Figure 4, obvious NOE signals between UPy motif $\left(\mathrm{H}_{2 \mathrm{a}}, \mathrm{H}_{2 \mathrm{~b}}\right.$, and $\left.\mathrm{H}_{2 \mathrm{c}}\right)$ and phenylene protons $\left(\mathrm{H}_{2 \mathrm{e}}\right)$ were observed. Additionally, correlation signals were also observed between 1-ethylpentyl group of the UPy and phenylene protons $\left(\mathrm{H}_{2 \mathrm{e}}\right)$. These evidences indicated that $\mathbf{M} 2$ formed a cyclic monomer structure via quadruple hydrogen bonding. The NOESY of M3 showed no similar correlation. It might be due to the longer distance between the dioxyphenylene group and the dimerized UPy motif in the cyclic form of M3.

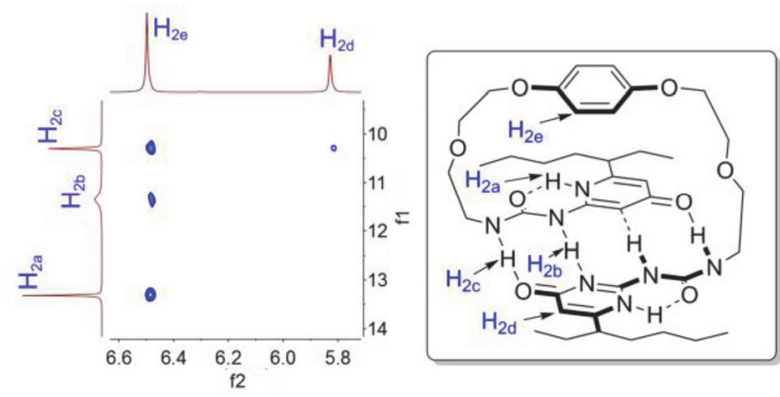

Figure 4 Partial NOESY NMR spectrum $\left(400 \mathrm{MHz}, \mathrm{CDCl}_{3}\right.$, $298 \mathrm{~K})$ of $\mathbf{M 2}\left(64 \mathrm{mmol} \cdot \mathrm{L}^{-1}\right)$

Viscosity measurements is a powerful tool to study supramolecular polymerization. To further investigate the ring-opening supramolecular polymerization process of M1 M3, viscosity measurements were carried out in $\mathrm{CHCl}_{3}$ solution. Double logarithmic plots of specific viscosity versus molecule concentration are shown in Figure 5. At the beginning of the concentration increasing, a slope of ca. 1 was observed for all curves, which is characteristic for non-interacting assemblies with constant size. This suggests the predominance of cyclic species below CPC. Upon increasing the concentration, M1 quickly shows the turning point at $7 \mathrm{mmol} \cdot \mathrm{L}^{-1}(\mathrm{CPC})$ and a moderate rise in the viscosity $\left(k_{M 1}^{\prime}=1.93\right)$. The CPC value is close to the ${ }^{1} \mathrm{H}$ NMR result $\left(5 \mathrm{mmol} \cdot \mathrm{L}^{-1}\right)$. By contrast, $\mathbf{M} 2$ showed a turning point at a relatively high concentration and a very steep slope was observed $\left(k_{\mathbf{M} 2}^{\prime}=8.70\right)$. The CPC value of $\mathbf{M 2}$ measured by viscosity $\left(191 \mathrm{mmol} \cdot \mathrm{L}^{-1}\right)$ is also in accordance with ${ }^{1} \mathrm{H}$ NMR result $\left(189 \mathrm{mmol} \cdot \mathrm{L}^{-1}\right)$. Different from M1 and M2, M3 showed a moderate CPC value of 55 $\mathrm{mmol} \cdot \mathrm{L}^{-1}$ and a moderate turning slope $\left(k_{\mathbf{M} 3}^{\prime}=5.71\right)$, which is also in agreement with the results from concentration-varied ${ }^{1} \mathrm{H}$ NMR of M3. Subsequently, the viscosity measurements again show the big impact of spacer length on the ring-opening supramolecular polymerization.
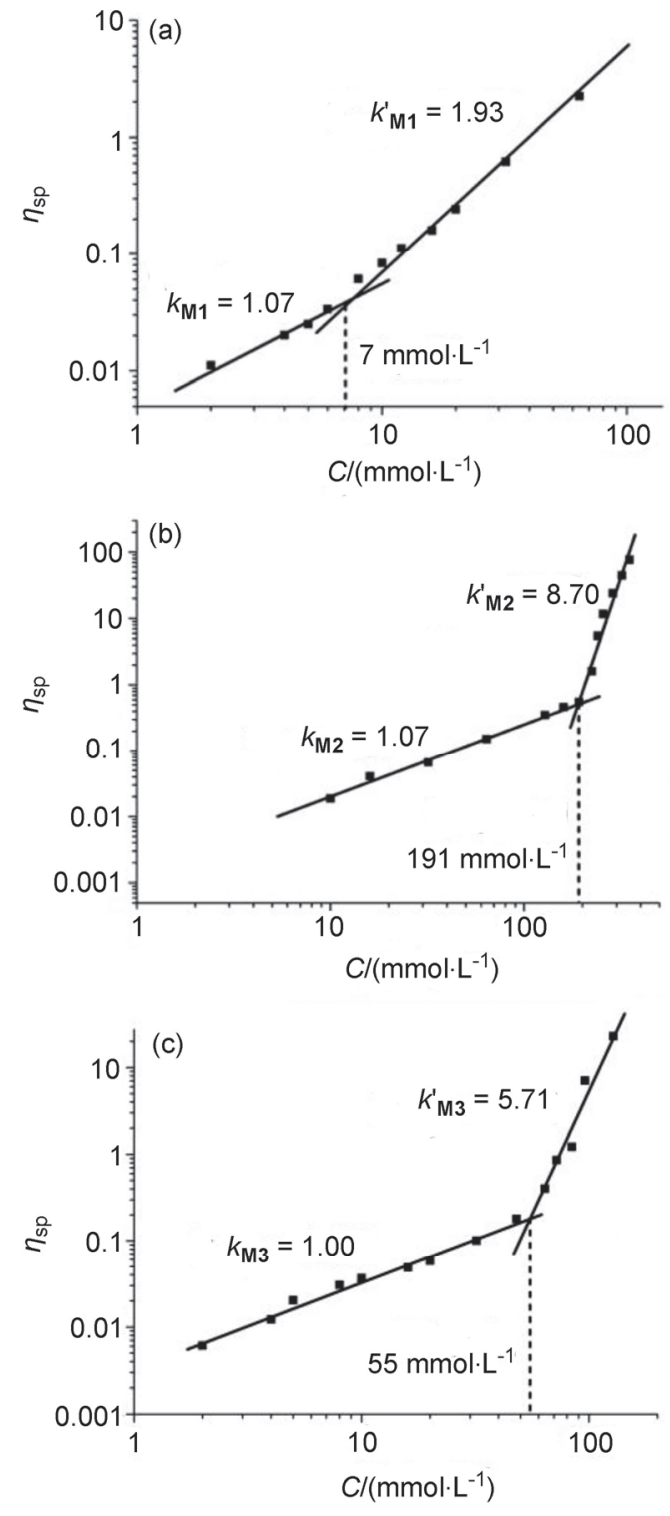

Figure 5 Specific viscosity of chloroform solutions of M1 (a), M2 (b), and M3 (c) against the concentration (298 K)

Values on the curves indicate the slope

Considering that the dioxyphenylene moiety is an electron rich group that can form mechanically interlocked molecules with electron deficient cyclophane, we envisioned what differences would happen in the host-guest complexation of $\mathbf{M 1} \sim \mathbf{M 3}$ with blue-box ${ }^{[43-44]}$ (also named as $\mathrm{CBPQT}^{4+}$ ). Notably, we have demonstrated that the ethylpentyl UPy motif could thread into the blue-box. ${ }^{[39]}$ The host-guest complexation of $\mathbf{M 1} \sim \mathbf{M} 3$ with blue-box in mixed $\mathrm{CHCl}_{3} / \mathrm{CH}_{3} \mathrm{CN}$ solvent was investigated. Interestingly, $\mathbf{M 3}+\mathrm{CBPQT}^{4+}$ exhibited red color (Figure 6), indicating the existence of host-guest complexation and formation of a hydrogen bonded [2]catenane, which was verified in our previous report. ${ }^{[39]}$ However, neither M1 nor M2 showed any evidence of complexation with $\mathrm{CBPQT}^{4+}$, resulting in a colorless solution with white precipitate after several days even heating to $50{ }^{\circ} \mathrm{C}$. The reason for M1 should be due to the short spacer, which has a very poor 
binding ability with $\mathrm{CBPQT}^{4+} \cdot{ }^{[45]}$ By contrast, the reason for $\mathbf{M 2}$ is because it forms a more stable cyclic monomer in dilute solution, which prevents its threading behavior with the blue-box. Compared with M2, the cyclic monomer of M3 is less stable and can undergo threading after ringopening. The colorless solutions of $\mathbf{M 1}+\mathrm{CBPQT}^{4+}$ and $\mathbf{M 2}+\mathrm{CBPQT}^{4+}$ also suggests that both $\mathbf{M 1}$ and $\mathbf{M} 2$ could not form relatively strong [2]pseudorotaxane with blue-box in $\mathrm{CHCl}_{3}$. Then the threading behavior in dimethyl sulfoxide (DMSO) was studied, which can totally break quadruple hydrogen bonding. According to ${ }^{1} \mathrm{H}$ NMR, no [2]pseudorotaxane was found in $\mathbf{M 1}+\mathrm{CBPQT}^{4+}$ while very few [2]pseudorotaxanes were formed in $\mathbf{M 2}+\mathrm{CBPQT}^{4+}$. By contrast, considerable amounts of [2]pseudorotaxane were formed in $\mathbf{M 3}+\mathrm{CBPQT}^{4+}$. These phenomena further indicate that the longer the ethylene glycol chain, the greater the ability to thread the ring of blue-box.

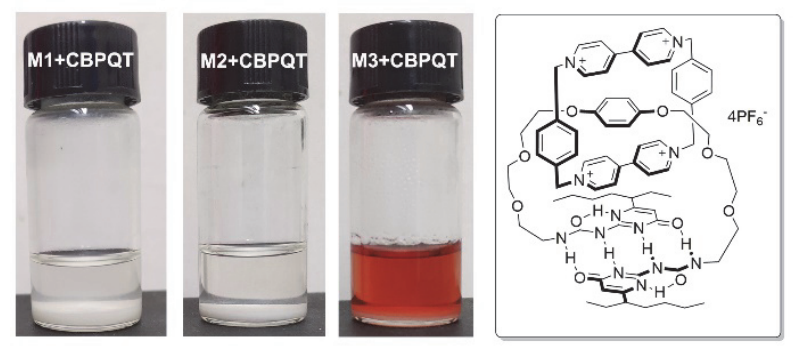

Figure 6 Pictures of mixture of M1, M2 and M3 with $\mathrm{CBPQT}^{4+}$ in mixed $\mathrm{CHCl}_{3} / \mathrm{CH}_{3} \mathrm{CN}$ solvent $(V: V=1: 1)$ (left) and chemical structure of [2] catenane formed from $\mathbf{M 3}+\mathrm{CBPQT}^{4+}$ (right)

\section{Conclusions}

In conclusion, we have described a ring-chain equilibrium supramolecular polymerization system based on quadruple hydrogen bonding, in which the spacer length of the monomers has a big influence on the ring-opening process. A combination of techniques including concentration-dependent ${ }^{1} \mathrm{H}$ NMR, NOESY and viscosity measurement were employed to study this system. Moreover, the host-guest complexation between the monomers with the $\pi$-electron deficient macrocycle "blue-box" were also investigated. From this interesting model, new insight into the relationship between molecular structure and supramolecular polymerization is discovered, which is important to create tailor-made supramolecular polymeric materials.

\section{Experimental section}

\subsection{Materials and instruments}

The commercially available reagents and solvents were either employed as purchased or dried according to procedures described in the literature. Compounds $\mathbf{1 a},{ }^{[46]} \mathbf{2},{ }^{[47]}$ $\mathbf{M 2},{ }^{[38]}$ and $\mathbf{M} 3^{[39]}$ were prepared according to literature procedure. All yields were given as isolated yields. NMR spectra were recorded on a Bruker AVANCE III $300 \mathrm{MHz}$ or a Bruker AVANCE III $400 \mathrm{MHz}$ spectrometer with in- ternal standard tetramethylsilane (TMS) and solvent signals as internal references, where $\mathrm{CDCl}_{3}$ and $\mathrm{CD}_{3} \mathrm{CN}$ were dried using neutral aluminum oxide. NOESY experiments were performed on a Bruker AVANCE III $400 \mathrm{MHz}$ spectrometer. Low-resolution electrospray ionization mass spectra (LR-ESI-MS) were obtained on LCMS2020. High-resolution electrospray ionization mass spectra (HR-ESI-MS) were recorded on an Agilent Technologies 6540 UHD Accurate-Mass. Viscosity measurements were carried out with Ubbelohde micro viscometers (Shanghai Liangjing Glass Instrument Factory, $0.40 \mathrm{~mm}$ inner diameter) at $298 \mathrm{~K}$ in chloroform.

\subsection{Synthesis of compound M1}

Imidazolide $2(0.68 \mathrm{~g}, 2.24 \mathrm{mmol})$ and $\mathbf{1 a}(0.20 \mathrm{~g}, 1.01$ mmol) were dissolved in dry $\mathrm{CHCl}_{3}(30 \mathrm{~mL})$ and this solution was stirred for $12 \mathrm{~h}$ under nitrogen at room temperature. To the reaction mixture $\mathrm{CHCl}_{3}(20 \mathrm{~mL})$ was added and the organic layer was washed with $1 \mathrm{~mol} / \mathrm{L} \mathrm{HCl}(50 \mathrm{~mL})$, saturated $\mathrm{NaHCO}_{3}(50 \mathrm{~mL})$, brine $(50 \mathrm{~mL})$, and then dried over anhydrous $\mathrm{MgSO}_{4}$ and concentrated under reduced pressure. The resulting residue was subjected to column chromatography over silica gel $\left(\mathrm{CHCl}_{3} / \mathrm{MeOH}, V: V=\right.$ $100: 1)$ to afford compound $\mathbf{M} 1$ as a colorless viscous solid (0.50 g, $0.75 \mathrm{mmol}, 74 \%)$. m.p. $263 \sim 265{ }^{\circ} \mathrm{C} ;{ }^{1} \mathrm{H}$ NMR $\left(300 \mathrm{MHz}, \mathrm{CDCl}_{3}\right) \delta: 13.13$ (s, 2H, NH), 12.04 (s, 2H, NH), $10.50(\mathrm{~s}, 2 \mathrm{H}, \mathrm{NH}), 6.85(\mathrm{~s}, 4 \mathrm{H}, \operatorname{ArH}), 5.82(\mathrm{~s}, 2 \mathrm{H}$, alkylidene-H), $4.06\left(\mathrm{t}, J=5.7 \mathrm{~Hz}, 4 \mathrm{H}, \mathrm{OCH}_{2}\right), 3.73 \sim 3.58$ (m, $\left.4 \mathrm{H}, \mathrm{OCH}_{2}\right), 2.36 \sim 2.23\left[\mathrm{~m}, 2 \mathrm{H}, \mathrm{CH}\left(\mathrm{CH}_{2}\right)_{2}\right], 1.73 \sim$ $1.50\left(\mathrm{~m}, 8 \mathrm{H}, \mathrm{CH}_{2}\right), 1.35 \sim 1.21\left(\mathrm{~m}, 8 \mathrm{H}, \mathrm{CH}_{2}\right), 0.92 \sim 0.85$ $\left(\mathrm{m}, 12 \mathrm{H}, \mathrm{CH}_{3}\right) ;{ }^{13} \mathrm{C}$ NMR $\left(75 \mathrm{MHz}, \mathrm{CDCl}_{3}\right) \delta: 173.1,157.1$, $155.4,154.7,153.1,115.7,106.4,67.0,45.4,39.4,32.9$, 29.3, 26.6, 22.5, 13.9, 11.7; ESI-MS $m / z: 667.25\left([\mathrm{M}+\mathrm{H}]^{+}\right)$, $665.20\left([\mathrm{M}-\mathrm{H}]^{-}\right)$; HR-ESI-MS calcd for $\mathrm{C}_{34} \mathrm{H}_{51} \mathrm{~N}_{8} \mathrm{O}_{6}$ $[\mathrm{M}+\mathrm{H}]^{+}$667.3926, found 667.3922.

Supporting Information Characterization spectra of compound M1 and ${ }^{1} \mathrm{H}-{ }^{1} \mathrm{H}$ NOESY of M2. The Supporting Information is available free of charge via the Internet at http://sioc-journal.cn.

\section{References}

[1] Wehner, M.; Würthner, F. Nat. Rev. Chem. 2020, 4, 38.

[2] Yang, L.; Tan, X.; Wang, Z.; Zhang, X. Chem. Rev. 2015, 115, 7196.

[3] Huang, F.; Scherman, O. A. Chem. Soc. Rev. 2012, 41, 5879.

[4] Aida, T.; Meijer, E. W.; Stupp, S. I. Science 2012, 335, 813.

[5] Brunsveld, L.; Folmer, B. J.; Meijer, E. W.; Sijbesma, R. P. Chem. Rev. 2001, 101, 4071.

[6] Park, T.; Zimmerman, S. C. J. Am. Chem. Soc. 2006, 128, 11582.

[7] Hirschberg, J. H. K. K.; Brunsveld, L.; Ramzi, A.; Vekemans, J. A. J. M.; Sijbesma, R. P.; Meijer, E. W. Nature 2000, 407, 167.

[8] He, M.; Chen, X.; Liu, D.; Wei, D. Chin. Chem. Lett. 2019, 30, 961.

[9] Würthner, F.; Saha-Möller, C. R.; Fimmel, B.; Ogi, S.; Leowanawat, P.; Schmidt, D. Chem. Rev. 2016, 116, 962.

[10] Bentz, K. C.; Cohen, S. M. Angew. Chem., Int. Ed. 2018, 57, 14992.

[11] Li, Z.; Gu, J.; Qi, S.; Wu, D.; Gao, L.; Chen, Z.; Guo, J.; Li, X.; Wang, Y.; Yang, X.; Tu, Y. J. Am. Chem. Soc. 2017, 139, 14364.

[12] Wang, X.; Han, Y.; Liu, Y.; Zou, G.; Gao, Z.; Wang, F. Angew. 
Chem., Int. Ed. 2017, 56, 12466.

[13] Xu, Y.; Wang, W.; Chen, J.; Lin, S. Chin. J. Org. Chem. 2018, 38, 2161 (in Chinese) (徐悦莹, 王伟, 陈健壮, 林绍梁, 有机化学, 2018, 38, 2161.)

[14] Xiao, T.; Zhou, L.; Xu, L.; Zhong, W.; Zhao, W.; Sun, X.-Q.; Elmes, R. B. P. Chin. Chem. Lett. 2019, 30, 271.

[15] Xiao, T.; Zhong, W.; Zhou, L.; Xu, L.; Sun, X.-Q.; Elmes, R. B. P.; Hu, X.-Y.; Wang, L. Chin. Chem. Lett. 2019, 30, 31.

[16] Chen, Y.; Sun, S.; Lu, D.; Shi, Y.; Yao, Y. Chin. Chem. Lett. 2019, 30,37

[17] Dong, S.; Zheng, B.; Wang, F.; Huang, F. Acc. Chem. Res. 2014, 47, 1982.

[18] Guo, D.-S.; Liu, Y. Chem. Soc. Rev. 2012, 41, 5907.

[19] Huo, B.; Li, B.; Su, H.; Zeng, X.; Xu, K.; Cui, L. Chin. J. Org. Chem. 2019, 39, 1990 (in Chinese).

(霍博超, 李斌, 苏杭, 曾宪强, 徐凯迪, 崔雷, 有机化学, 2019, 39, 1990.)

[20] Wang, Y.; Ping, G.; Li, C. Chem. Commun. 2016, 52, 9858.

[21] Dai, D.; Li, Z.; Yang, J.; Wang, C.; Wu, J. R.; Wang, Y.; Zhang, D.; Yang, Y. W. J. Am. Chem. Soc. 2019, 141, 4756.

[22] Wang, Q.; Chen, Y.; Liu, Y. Polym. Chem. 2013, 4, 4192.

[23] Shi, Z. M.; Wu, C. F.; Zhou, T. Y.; Zhang, D. W.; Zhao, X.; Li, Z. T. Chem. Commun. 2013, 49, 2673.

[24] Wei, P.; Yan, X.; Huang, F. Chem. Soc. Rev. 2015, 44, 815.

[25] Sijbesma, R. P.; Beijer, F. H.; Brunsveld, L.; Folmer, B. J. B.; Hirschberg, J. H. K. K.; Lange, R. F. M.; Lowe, J. K. L.; Meijer, E. W. Science 1997, 278, 1601.

[26] Zhang, T.; Ma, X.; Tian, H. Chem. Sci. 2020, 11, 482.

[27] Yan, X.; Liu, Z.; Zhang, Q.; Lopez, J.; Wang, H.; Wu, H. C.; Niu, S.; Yan, H.; Wang, S.; Lei, T.; Li, J.; Qi, D.; Huang, P.; Huang, J.; Zhang, Y.; Wang, Y.; Li, G.; Tok, J. B.; Chen, X.; Bao, Z. J. Am. Chem. Soc. 2018, 140, 5280 .

[28] Qin, B.; Zhang, S.; Song, Q.; Huang, Z.; Xu, J. F.; Zhang, X. Angew. Chem., Int. Ed. 2017, 56, 7639.

[29] Peng, H.-Q.; Zheng, X.; Han, T.; Kwok, R. T. K.; Lam, J. W. Y.; Huang, X.; Tang, B. Z. J. Am. Chem. Soc. 2017, 139, 10150.

[30] Goujon, A.; Mariani, G.; Lang, T.; Moulin, E.; Rawiso, M.; Buhler, E.; Giuseppone, N. J. Am. Chem. Soc. 2017, 139, 4923.

[31] Peng, H.-Q.; Sun, C.-L.; Niu, L.-Y.; Chen, Y.-Z.; Wu, L.-Z.; Tung,
C.-H.; Yang, Q.-Z. Adv. Funct. Mater. 2016, 26, 5483.

[32] Fu, X.; Gu, R.-R.; Zhang, Q.; Rao, S.-J.; Zheng, X.-L.; Qu, D.-H.; Tian, H. Polym. Chem. 2016, 7, 2166.

[33] Wang, Q.; Zhang, P.; Li, Y.; Tian, L.; Cheng, M.; Lu, F.; Lu, X.; Fan, Q.; Huang, W. RSC Adv. 2017, 7, 29364

[34] Xiao, T.; Zhou, L.; Wei, X.; Li, Z.; Sun, X. Chin. J. Org. Chem. 2020, 40, 944 (in Chinese).

(肖唐金金, 周玲, 魏小艳, 李正义, 孙小强, 有机化学, 2020,40 , 944.)

[35] Xiao, T.; Xu, L.; Wang, J.; Li, Z.-Y.; Sun, X.-Q.; Wang, L. Org. Chem. Front. 2019, 6, 936.

[36] Xiao, T.; Xu, L.; Götz, J.; Cheng, M.; Würthner, F.; Gu, J.; Feng, X.; Li, Z.-Y.; Sun, X.-Q.; Wang, L. Mater. Chem. Front. 2019, 3, 2738 .

[37] Guo, D.; Sijbesma, R. P.; Zuilhof, H. Org. Lett. 2004, 6, 3667.

[38] Xiao, T.; Zhong, W.; Qi, L.; Gu, J.; Feng, X.; Yin, Y.; Li, Z.-Y.; Sun, X.-Q.; Cheng, M.; Wang, L. Polym. Chem. 2019, 10, 3342.

[39] Xiao, T.; Li, S.-L.; Zhang, Y.; Lin, C.; Hu, B.; Guan, X.; Yu, Y.; Jiang, J.; Wang, L. Chem. Sci. 2012, 3, 1417.

[40] de Greef, T. F. A.; Meijer, E. W. Nature 2008, 453, 171.

[41] Hu, X.-Y.; Zhang, P.; Wu, X.; Xia, W.; Xiao, T.; Jiang, J.; Lin, C.; Wang, L. Polym. Chem. 2012, 3, 3060

[42] Li, S.-L.; Xiao, T.; Xia, W.; Ding, X.; Yu, Y.; Jiang, J.; Wang, L. Chem.-Eur. J. 2011, 17, 10716.

[43] Zhang, K.-D.; Zhao, X.; Wang, G.-T.; Liu, Y.; Zhang, Y.; Lu, H.-J.; Jiang, X.-K.; Li, Z.-T. Angew. Chem., Int. Ed. 2011, 50, 9866.

[44] Liu, M.; Li, S.; Zhang, M.; Zhou, Q.; Wang, F.; Hu, M.; Fronczek, F. R.; Li, N.; Huang, F. Org. Biomol. Chem. 2009, 7, 1288.

[45] Anelli, P. L.; Ashton, P. R.; Ballardini, R.; Balzani, V.; Delgado, M.; Gandolfi, M. T.; Goodnow, T. T.; Kaifer, A. E.; Philp, D.; Pietraszkiewicz, M.; Prodi, L.; Reddington, M. V.; Slawin, A. M. Z.; Spencer, N.; Stoddart, J. F.; Vicent, C.; Williams, D. J. J. Am. Chem. Soc. 1992, 114, 193.

[46] Tsukamoto, T.; Sasahara, R.; Muranaka, A.; Miura, Y.; Suzuki, Y.; Kimura, M.; Miyagawa, S.; Kawasaki, T.; Ko-bayashi, N.; Uchiyama, M.; Tokunaga, Y. Org. Lett. 2018, $20,4745$.

[47] Keizer, H. M.; Sijbesma, R. P.; Meijer, E. W. Eur. J. Org. Chem. 2004, 2004, 2553. 